Fantasy Paradigms of Health Inequalities: utopian thinking?

Authors: Scott-Samuel, A. ${ }^{1 *}$ and Smith, K.E. ${ }^{2}$

${ }^{1}$ Department of Public Health and Policy, University of Liverpool, Whelan Building, Liverpool, L69 3GB, UK. Tel 0044-151-794-5569. E-mail alexss@liverpool.ac.uk

${ }^{2}$ Global Public Health Unit, School of Social \& Political Science, University of Edinburgh

* Corresponding author (alexss@liverpool.ac.uk) 


\section{Fantasy Paradigms of Health Inequalities: utopian thinking?}

\section{Abstract}

This paper argues that, while it can be politically expedient for governments to engage with health inequalities, they cannot, within the confines of neoliberalism, realistically propose actions that evidence suggests will effectively reduce them - such as tackling power inequalities, social status and connections or class inequality. Indeed, a dominant 'policy paradigm' prioritising economic growth restricts the ability of policy actors to imagine alternative, more equitable scenarios. In this context, some policy actors and researchers have devised a parallel fantasy world in which proximal, downstream, easily-tackled exposures are posited as potential solutions to health inequalities. The consequence of this is a widespread public sector culture in which well-meaning policy-makers, practitioners, researchers and members of the public collude in sustaining a 'cargo cult' of health behaviourism. In examining this situation, we draw on accounts and critiques of utopian thinking to help explain: (i) the remarkable persistence of policy proposals to tackle health inequalities via downstream interventions, in spite of the strength of evidence challenging such approaches; and (ii) the limited extent to which more upstream proposals inform policy debates. We argue Ruth Levitas' notion of 'utopia as method' offers an imaginative and potentially useful avenue for future health inequalities research.

Abstract word count: 199

Keywords: Health inequalities; neoliberalism; utopian; power; evidence-based policy; health behaviourism 


\section{Introduction}

It is now widely accepted that health inequalities - unfair, unjust differences in health determinants and outcomes within and between populations - have serious immediate and long-term negative impacts on individuals and societies (Drever and Whitehead, 1997; Department of Health, 1998; Commission on Social Determinants of Health, 2008; Marmot Review, 2010). As a result, many governments across the world have, at minimum, a rhetorical commitment to the reduction of health inequalities (see Commission on Social Determinants of Health, 2008 for an overview). In some countries, notably the UK, such policies may even acknowledge that the causes of health inequalities rest with material and social factors such as poverty, poor housing and social exclusion (Smith et al, 2009). It is, however, exceptional for national inequality reduction strategies to include more than a brief acknowledgement of these meso-level factors and even rarer to find an analysis of the causal pathways that result in the unequal distribution of these factors; the 'upstream' macro-level determinants shaping the structure of society. Indeed, when it comes to setting out visions for reducing health inequalities such strategies tend to provide a list of interventions that focus almost entirely on 'downstream' (proximal) health determinants such as smoking, unhealthy dietary choices, poor housing conditions, or failure to use contraception - implying that it is the social patterning of these factors which represent the causes of health inequalities (see Popay et al, 2010; Smith et al, 2009; Smith, 2013a).

There are however persuasive reasons to believe that health inequalities will only be reduced as a result of substantially more fundamental policy change (see Scott et al, 2013). Health inequalities are increasingly viewed as an outcome of material, social and cultural inequalities across societies (Krieger, 2001; Whitehead and Dahlgren, 2007; Wilkinson and Pickett, 2009; Krieger et al, 2010) which are, in turn, the product of inequalities in power 
(Bambra et al, 2005; Schulz and Mullings, 2006), income and wealth, knowledge, social status and social connections (Link and Phelan, 1995). Viewed from this perspective, sustained long-term reductions in health inequalities are almost certainly dependent on strategies that engage effectively with these root causes (Phelan et al, 2004; Scott et al, 2013).

The persistence of health inequalities provides further justification for revising the focus required to achieve effective policy action. Differences in health and survival between more and less advantaged population subgroups have persisted across centuries (Davey Smith et al, 2001; Drever and Whitehead, 1997; Bartley, 2003; Mackenbach, 2012). What has changed are the immediate proximal causes of those inequalities: premature death among the poor is now primarily the result of chronic conditions like cancers and cardiovascular diseases rather than infectious diseases, as was formerly the case. What remains unchanged is that people living in poorer circumstances still die prematurely - and even targeted health inequalities policies and strategies appear to have had little or no impact (Mackenbach, $2010 ; 2011)$.

One obvious explanation for this phenomenon of ineffective political action on health inequalities is that politicians are attracted by non-controversial, relatively low-cost policy options which can be implemented in a short timeframe (within electoral cycles). Thus, it is far easier to focus on exhorting downstream 'lifestyle changes', such as encouraging people to smoke less, eat more healthily, drink less alcohol and exercise more, than it is to legislate for 'midstream' policies such as those limiting the marketing and availability of tobacco, junk food and alcohol (e.g. through standardised packaging of cigarettes), or providing more 
cycle lanes on highways. Although some midstream policies (especially, in recent times, those focusing on tobacco control) have been explored, it seems hard to even imagine what policies attempting to substantively engage with power inequalities, or any of the other upstream causes listed above, might look like. In a capitalist society, where liberal macroeconomic policy positions virtually all economic activity - including unhealthy activity - as beneficial, there is an inbuilt incentive to 'blame the victim' rather than to tackle the corporate and economic causes of the problem (Crawford, 1977; Collin, 2012; Freudenberg, 2014).

Those who do actively call attention to the need to tackle the root causes of health inequalities are often accused of being 'unrealistic', 'ideologically driven' or worse (Smith, 2013a). Professors Richard Wilkinson and Kate Pickett, the authors of the widely read 2009 book The Spirit Level (2009) and founders of The Equality Trust, have, for example, been labelled 'delusional' (Snowdon, 2010) and 'false prophets' (Saunders, 2010) on the basis of their attempts to make the case for a more equal society. In contrast, in this paper, we draw on the work of various scholars who have promoted the utility of utopian thinking, but notably Ruth Levitas' (2013) idea of 'utopia as method', to argue that: (i) if we take the commonly held view of 'utopia' as 'fantastical' and 'unrealistic', then it is current policy commitments to reducing health inequalities that are 'utopian'; and (ii) if we accept an alternative framing of utopia as a necessary means of exploring alternative future scenarios, then those seeking to reduce health inequalities could benefit from utopian thinking. In other words, we are arguing that research on health inequalities needs to move beyond an analysis of how things currently are to consider how things could be (Levitas, 2013). 


\section{Fantastical visions of tackling health inequalities in the UK}

In the UK, as in other countries with a history of welfare state development, the public sector occupies an important role in the determination of health inequalities. This is governed via a centralised style of government which generally allows little local flexibility on the part of public authorities in their allocative role with the social determinants of health - such as access to social housing, education, state benefits, or health / public health services and policies. When this level of control is combined with a dominant political paradigm which prioritises economic growth above social and environmental wellbeing (Dietz and O'Neill, 2013), the possibilities for local innovation to tackle health inequalities are minimised. As a result, local public services such as the National Health Service (NHS) and local government, as well as voluntary 'third sector' services (which are also becoming providers of health and social care as governments 'roll back the welfare state' [Chaney and Wincott, 2014]), have increasingly sung to the national government's tune in their engagement with health inequalities. Hence, our focus here, is on national government policy efforts to reduce health inequalities.

Our focus is on England / the UK in the period since 1997, the point at which health inequalities re-emerged as an official policy concern (Bartley et al, 1998), although we note, in the concluding discussion, that many of these observations are likely to have relevance for countries pursuing similar economic and welfare policies. The Thatcher-led Conservative government, in power from 1979-90, refused to engage in any way with health inequalities (Scott-Samuel et al, 2014) and its successor, the Major Conservative government, in power from 1990-97, acknowledged only that there were 'health variations', with government responsibility explicitly restricted to Whitehall and NHS policy (Department of Health, 1995). 
The Blair-led Labour government came to power in 1997 after 18 years in which Labour had, in opposition, frequently and consistently emphasised the importance of addressing health inequalities and was elected on the basis of a manifesto which included a clear commitment to reducing health inequalities (Labour Party, 1997). Indeed, Labour's - and England's - first Minister for Public Health, Tessa Jowell, travelled the country in the summer of 1997 telling public health audiences that they 'should feel free once again to use the word inequalities' something they had effectively been prevented from doing during 18 years of Conservative government as a result of the centrally dominated public sector culture (see, for example, Bartley et al, 1998).

Yet, while the NHS public health services and local authorities now had a new song to sing regarding health inequalities, it was very clearly a two-part harmony. Following the publication by the Labour government of the Health Inequalities Decennial Supplement (Drever and Whitehead, 1997) and the government-commissioned Acheson Inquiry (Acheson et al, 1998), both of which were wide-ranging and relatively radical in their review of health inequalities trends and research, a series of government pronouncements and strategies emerged over the next decade in which rhetoric was not translated into policy action (Department of Health, 2003; Department of Health, 2008). While much emphasis was given in these and other reports to addressing wider determinants of health, in practical terms, new government public health resources were largely allocated to individualistic interventions such as behaviour modification programmes (NICE, 2007). Local public health and health promotion practitioners had very little encouragement, flexibility or even capacity to address 'upstream' issues, even if they wanted to (Springett and ScottSamuel, 2007). 
What existed, then, during the period of Labour government (1997-2010) and what continued during the period of Conservative - Liberal Democrat Coalition government which succeeded it (2010-15), was a government-led NHS, local authority and third sector fantasy paradigm in which health inequalities were positioned as an issue that could be effectively tackled via interventions aiming to challenge lifestyle differences between population subgroups - in particular, social classes (Smith, 2013a). Hence, despite the fact that official government documents and speeches have repeatedly, since 1997, acknowledged the underlying social and economic causes of health inequalities, they have also, as many researchers have noted, advocated the idea that health inequalities can be effectively reduced via short-term individual action (see, for example, Smith et al, 2009; Popay et al, 2010). This paradigm has been promoted and reproduced by a large body of state / third sector employees, who have developed diverse plans and projects, supported by public and other funds, to implement a wide range of downstream, outcome-focused activities in the name of reducing health inequalities. This is despite that fact that there is strong evidence that health inequalities are largely unaffected by these approaches (Phelan et al, 2004; Scott et al, 2013) and, indeed, that such interventions may exacerbate health inequalities (Lorenc et al, 2012 Whitehead, 2007).

An equally large body of quantitative knowledge in the form of indicators, targets, monitoring tools and other performance measures has been developed to assess this programme of activity. The frequent demonstrations of failure are typically explained with reference to the 'challenging and persistent nature' of health inequalities (e.g. Department of Health, 2009). Especially notable was the post-2010 Coalition government's continuing 
rhetorical attachment to the reduction of health inequalities, despite the same government's systematic dismantling of public sector mechanisms for supporting people experiencing poverty, disadvantage and inequality (O'Hara, 2014).

Yet, if we accept the notion that health inequalities are the result of upstream inequalities in power and material resources, then it is of course a logical impossibility that these inequalities can be reduced under an economic system which prioritises economic growth and leads, inevitably, to a concentration of wealth (Piketty, 2014). In other words, in a neoliberal regime predicated on inequality, policy commitments to reducing health inequalities are 'utopian', at least if we take the popular interpretation of this term as representing fantastical, impossible dreams of society which will almost certainly not come to fruition (Goodwin and Taylor, 1982; Levitas, 2013).

A variety of popular theories about the policymaking process help explain why it has been so hard to achieve the degree of policy change that many researchers believe is required to address health inequalities in the UK (Smith and Mor Kandalik, 2015). For example, Peter Hall's (1993) notion of 'policy paradigms' and Vivien Schmidt's (2010) concept of 'discursive institutionalism' can each be employed to help explain how a medical model of health and free-market oriented economic policies have been institutionalised and normalised in ways which conspire to 'filter out' ideas about health inequalities which do not 'fit' with these ideas (e.g. Smith, 2013b). Likewise, John Kingdon's (1995[1984]) ideas about the need for three distinct 'policy streams' to converge to enable meaningful policy change can help explain why research-informed ideas about health inequalities have failed to translate into substantive policy action at a local level (e.g. Exworthy et al, 2002). It is a rather different 
matter to reflect on why, despite the obvious tensions with the existing political and economic context, both the Labour governments of 1997-2010 and the Conservative-Liberal Democrat coalition government of 2010-2015 decided to make formal commitments to reducing health inequalities and why only a handful of academics writing about health inequalities have overtly highlighted these tensions (e.g. Scambler, 2007; 2009; 2012).

Indeed, it is fascinating to consider the confusion of values that underlies current policy commitments to reducing health inequalities which, whilst rhetorically acknowledging the need to tackle underlying inequalities in wealth and power, are put forward in a political and economic system that drives, and depends, on these inequalities. One way of exploring this is to identify the visions of future society that are implied by current policy commitments; the kind of critical academic work that is more common in sociology and geography than in schools of health or medicine (e.g. Scambler, 2007; Slater, 2014). As Levitas notes in the opening section of Utopia as Method:

'while socialist and environmentalist politics are easily labelled utopian, implying a mix of radical alterity and impossibilism, it is important to recognize the utopianism of right-wing politics, both at the level of improvised institutions and especially at the level of the state and the global market. Many social practices and most political programmes embed an idea of the good society and attempt to implement it.' (Levitas, 2013: xiii)

Reflecting on current public policy and political debate in England, it seems hard to identify any clear vision of the good society. Rather, there appears to be a longing either for health 
inequalities to disappear in a context in which other, related inequalities remain or, perhaps, for poorer groups themselves to disappear (McCormack and Pallister, 2009). On the one hand, policy commitments to reducing health inequalities point to a vision of a more equitable society (at least in health terms); on the other, there are multiple policy changes which appear to be intended to achieve a society in which the role of the public sector in providing social support is minimised (O'Hara, 2014) and efforts to alter the distribution of resources increasingly favour individuals and private sector actors who are already wealthy (Sayer, 2014). What is implied, it seems, is that the population of England can flourish by working hard to change their own individual circumstances. Precisely how they might do this en masse is less clear and remains, we argue, fantastical.

To make this point more clearly, we can examine how the assumptions and narratives evident with English policies compare to available evidence. One popular narrative is that individuals can, and should, change their circumstances by obtaining a job that pays them sufficiently well to enable them to move up the socio-economic ladder; or, in UK Prime Minister David Cameron's words, that those in difficult circumstances should 'work their way out of it' (Cameron, 2012). This narrative is particularly evident in 'welfare to work' interventions in the UK (Wright, 2012), many of which aim to 'empower' individuals to make more use of their 'assets' and realise their potential to work (Friedli, 2013). If achievable, this could place such individuals in a position to pay (more) for the resources they require to flourish (e.g. education, food, housing and health and social care services). However, whilst such a route can work for a small number of individuals, in a context in which there are relatively few well-paid, secure jobs available and many poorly paid, insecure, low quality 
jobs (Joyce et al, 2010; Shildrick et al, 2012), this is clearly not a route via which population level material inequalities are likely to be addressed.

Another narrative evident in English national policies (sometimes explicit, often implicit) is that national economic growth, and the success of large businesses and wealthy individuals, all benefit society as a whole. The (now rarely articulated) assumption here appears to be that wealth at the top will 'trickle down', benefitting everyone. This kind of assumption is evident in speeches made by the current (i.e. May, 2015) UK Chancellor of the Exchequer, George Osborne, in which he claims that policies that attract large banking firms to the UK 'bring jobs, investment and prosperity' (Osborne, 2013). Yet, the economic evidence suggests that income inequalities are increasing as wages in the lower quintiles stagnate (Stiglitz, 2012) and wealth becomes increasingly concentrated in the hands of a smaller number of people (Oxfam, 2015; Sayer, 2014), a phenomenon Hacker and Pierson (2010) term 'hyperconcentration'. Although the Labour governments in power from 1997 until 2010 made some attempt to address poverty, though a national minimum wage, tax credits and various area-based schemes (such as the Neighbourhood Renewal Fund), they demonstrated little, if any, concern with the hyperconcentration of wealth.

Finally, there is a narrative suggesting that, despite difficult circumstances, health inequalities can be tackled if poorer groups can somehow be persuaded to change their behaviours in ways which improve their health at such a rate that their health outcomes gradually catch up with the health outcomes of wealthier groups (e.g. Buck and Frosini, 2012). This is despite the fact that, as discussed above, government documents themselves acknowledge the wealth of evidence (e.g. Marmot, 2010) that highlights the fundamental, 
'upstream' causes of health inequalities as well as related research that highlights the potential for downstream interventions to increase health inequalities (Lorenc et al, 2012). Moreover, since 2011, policy approaches to tackling key public health issues linked to specific behaviours, such as alcohol and food consumption, have (in England at least) been informed by 'Public Health Responsibility Deals’ which involve collaborations between public, private and third sector actors. In other words, the financial interests that profit from health damaging products have been invited to participate in developing policy responses to the resulting health problems (Gilmore et al, 2011).

Hence, it is profoundly unclear how commitments to, and targets for, reducing health inequalities can possibly be achieved, at least not without substantial policy changes of a kind not currently being seriously considered.

\section{Limited visions within current health inequalities research}

So far, we have suggested that policy commitments to reducing health inequalities are 'utopian' on the basis that available evidence indicates that the kinds of programmes and activities being tried in England (and elsewhere) have not yet achieved, and are highly unlikely to achieve, substantial reductions in health inequalities (Mackenbach, 2011). The body of research focusing on health inequalities in England is substantial and growing on an almost weekly basis (Bambra et al, 2011). This research has usefully mapped patterns of health inequalities using a variety of social, economic and geographical criteria (e.g. Davey Smith et al, 2001), captured personal accounts of life in difficult circumstances that help explain social variations in particular lifestyle-behaviours (e.g. Graham, 1994), identified 
some of the root causes of health inequalities (e.g. Black et al, 1980; Marmot, 2010) and evaluated the impact of multiple policies and interventions on patterns of health inequalities (e.g. Lorenc et al, 2012). These achievements were particularly impressive in the pre-1997 era, when tackling health inequalities was not on the official policy agenda and when funding for research in this area was limited (Bartley et al, 1998).

What this body of research has struggled to offer, however, is a vision of a social, political and economic context in which health inequalities would be substantially reduced or any clear guidance as to how, in practical terms, such a vision might be achieved - a limitation that has led to some frustration among both policymakers and campaigners/advocates (Garthwaite et al, in press). The lack of practical recommendations has informed decisions by research funders to increasingly emphasise the need for intervention orientated and evaluative research (Garthwaite et al, in press). Yet, a belief that this kind of research can provide evidence-informed solutions to health inequalities is open to the criticisms made in the previous section, for the interventions available to evaluate are almost wholly relatively small-scale and 'downstream' in nature (Garthwaite et al, in press). Moreover, as Schrecker (2014) outlines, public health researchers largely remain committed to traditional hierarchies of evidence (with systematic reviews of randomised controlled trials as the 'gold standard') which prioritise research designs that cannot be easily applied to understanding the health and distributional impacts of macro-level political, economic and social change. Health inequalities are a complex phenomenon in which multiple factors are interacting and 'controlling for all but a single variable in the interests of methodological elegance or greater precision about causation simply disregards that reality' (Schrecker, 2014: 743). In other words, by continuing to apply traditional public health research designs to studying 
health inequalities and the impact of downstream interventions, large numbers of researchers are participating in, and helping to perpetuate, the fantasy that health inequalities can be substantially reduced without major social, political and economic change.

This may stem from a commitment to particular methodological standards, an altruistic desire to make a difference and/or personal career interests (given that it is easier to obtain funding for research which offers the potential of evidence-informed, viable policy solutions to health inequalities than for more ambitious and challenging academic projects - Smith, 2010). This is not a problem that is specific to the realm of health inequalities; as Fuller (2005) suggests, it is a tension that cuts across modern academia:

' $[\mathrm{P}]$ oliticians can capitalise on the endless ingenuity displayed by scientists - both natural and social - in adapting their research agendas to suit the needs of potential clients, so as to feed their own endless needs for funds. Moreover, the natural tendency of scientists to want to examine things more comprehensively, in greater detail and, of course, with an eye towards a renewal of their contract, nicely plays into politicians own propensity to temporize, whenever possible. Never have the worst character traits of two groups worked to such mutual advantage.' (Fuller 2005: p.136)

The restrictions on scholarly imagination within the social sciences are compounded, Goodwin and Taylor (1982) and Levitas (2013) suggest, by efforts by those forging emerging 
academic disciplines in the social sciences in the twentieth century to gain credibility for their work by aspiring to the label of 'science'. An important consequence of such efforts has been the widespread reification of empiricism and, within this, of quantitative methods over qualitative methods. For researchers concerned with society (in geography, sociology, social policy, politics and elsewhere), this usually means that 'society', as an object of study, is broken down into tangible, measurable units that are amenable to traditional scientific methods. This has limited the scope for work which aims to think more holistically about society as well as that which considers not only what is but what is intended to be and what might be (Levitas, 2013). The institutionalisation of distinct academic disciplines has further perpetuated the fragmentation of academic work which seeks to deal with complex, human systems.

\section{Rescuing the idea of 'utopian thinking' and imagining more equal societies}

Against this backdrop, utopian thinking has not always been popular (see, for example, Kateb, 1963) but there have been intermittent attempts to make a case for its utility, including by anthropologists (e.g. Mead, 1971) and political theorists (e.g. Goodwin and Taylor, 1982). Levitas' 2013 book, Utopia as Method, which is grounded within sociology, is one of the most recent attempts to rescue the idea of 'utopia', calling on academics interested in society to move beyond an analysis of the past and the present to consider, in a holistic sense, how future societies might 'become and be otherwise' (Levitas, 2013: 66):

'the Imaginary Reconstitution of Society intrinsically necessitates thinking about the connections between economic, social and political processes, our ways of life, and 
what is necessary to human flourishing. It requires a holistic approach fundamental to the distinctive character of sociology.' (Levitas, 2013: xv)

In this sense, Levitas is seeking, as Mead (1971) and Goodwin and Taylor (1982) did before her, to lessen the gap that has emerged in the post-Enlightenment period between what is considered to be the realm of 'literature' and what is considered to be 'science'. Here, focusing particularly on Levitas' (2013) recent account, we consider what taking the idea of utopia seriously might mean for scholars concerned with health inequalities.

Levitas, like many other proponents of utopia (e.g. Kumar, 1991; Goodwin and Taylor, 1982), argues that it is a concept that 'embodies the refusal to accept that living beyond the present is delusional, the refusal to take at face value current judgements of the good or claims that there is no alternative.' (Levitas, 2013: 17) The popular idea that 'utopia' necessitates 'totalitariansim' (e.g. Kolakowski, 1983), is Levitas argues, 'a political move that is intended to make any aspiration to social change impossible.' (Levitas, 2013: p8)

Critics of utopian thinking have frequently highlighted the impossibility of imagining a future society which appeals everyone; the well-known dictum being that one person's utopia is another's dystopia. For such critics, utopian visions are necessarily in conflict with the idea of democracy (Kolakowski, 1983). If, however, we conceive of utopian thinking not as the active promotion of an idealised sense of society, to be achieved at all costs (with the ensuing inevitability of totalitarian regimes), but rather as a means of engaging in a democratic debate about the 'potential contents and contexts of human flourishing' 
(Levitas, 2013: pxi), then it becomes easier to value the potential utility of utopian thinking. The idea, as Levitas (2013) puts it, is to conceive of utopia as a method, rather than a goal.

This is not, however, to suggest that utopian thinking ought to remain vague and aspirational in nature. Within health inequalities research, the utopian vision of a society in which health is more equal is ever-present. What is missing is much debate about the practical social, political and economic changes required to enact this vision. Indeed, this is a problem facing all of us who are concerned with the unequal consequences of current economic policy - it is not specific to health inequalities. Twenty years ago, feminist social historian of science Donna Haraway warned: " "I have almost lost the imagination of what a world that isn't capitalist could look like. And that scares me. ... It's not just in the United States. We are losing effective social imaginaries' (Haraway, Harvey et al., 1995: 519).

The need to develop, and articulate, clear visions of how society might potentially be is reinforced by a variety of theories of policy change. Max Weber, for example, argued that the self-perpetuating momentum of institutionalism within modern bureaucracies is only challenged by the 'charismatic' qualities associated with persuasive, alternative 'visions' of the future (Weber, 1968). Even theorists of more routine (less dramatic) policy change, such as John Kingdon (1995), place a great deal of emphasis on the importance of clear policy 'solutions' being actively promoted to policy audiences for policy change to be achieved.

What we are suggesting here is that scholars studying health inequalities need now to move beyond an analysis of patterns and causes of health inequalities to start to articulate explicit 
alternative future scenarios in which greater health equality could be achieved. Such scenarios cannot plausibly be dreamed up by academics working in isolation; this kind of work requires researchers to work alongside a variety of communities, perhaps especially those communities most negatively affected by health inequalities, in order to sketch out collaborative ideas for how our society might be organised and governed (in the vein that some of the academics involved in the UK Arts and Humanities Research Council's Connected Communities programme have begun to explore, e.g. Bitton et al, 2012). This will not, of course, be a method with which many health inequalities researchers are comfortable - it is a long way from "the reductionist epistemology that underscores most public health enterprise" (Chapman, 2007:.29) - and we are certainly not suggesting that all (or even most) researchers should attempt to employ utopian thinking as a method. In the cross-disciplinary field of health inequalities, this style of work may well sit more comfortably with researchers based in sociology and geography than those located within schools of medicine, for example. We are simply proposing that there ought to be more space within debates about health inequalities to reflect on what the extensive research we are amassing about these inequalities suggests about the kinds of social, political and economic conditions necessary for their substantial reduction.

This kind of 'social imaginary' is necessary, Mumford (1923) argues, to help us act in ways that overcome the momentum of existing institutions. Such scenarios will necessarily be provisional, contingent and open to criticism and adaption as our knowledge and circumstances change. The purpose is not to produce a roadmap to equality but rather to: 'develop alternative possible scenarios for the future and open these up to public debate and democratic decision - insisting always on the provisionality, reflectivity and contingency 
of what we are able to imagine, and in full awareness that utopian speculation is formed always in the double squeeze of what we are able to imagine and what we are able to imagine as possible.' (Levitas, 2013: 19).

For Levitas (2013) 'utopia as method' involves three inter-related activities. The first, the one with which critical scholars are perhaps most comfortable, is what Levitas calls 'utopia as archaeology'. This involves identifying, and making more explicit, the visions of, and assumptions about, society (especially what a 'good society' looks like) that are embedded within current social and economic policies and in political debates and programmes. The point here is to draw attention to the normative, ethical assumptions and preferences that are driving current policy decisions but which are often obfuscated by claims to 'evidencebased' decision-making and/or framings which suggest there is no alternative (a phrase popularised by the UK Prime Minister, Margaret Thatcher, during the 1980s). This is what we have (briefly) attempted in the first part of this paper.

The second, 'utopia as ontology', requires us to consider 'what kind of people societies develop and encourage' (Levitas, 2013: 153), what capabilities are valued and rewarded and which are disregarded or even blocked. This involves both reflecting on existing and past political, economic and social contexts and working with others to try to imagine alternatives. From the perspective of health inequalities, this might involve working with communities most negatively affected by health inequalities to discuss the ways in which existing and potential societies enable and disable, value and de-value, different kinds of people and the implications that this has for health outcomes and their societal distribution. 
The third strand, 'utopia as architecture' is perhaps the most ambitious, or at least the most uncomfortable for an academic endeavour situated within scientific norms. It involves trying to imagine and describe potential alternative societies, the institutions and structures which govern them and the consequences for the people who inhabit them. In other words, from the perspective of those interested in reducing health inequalities, this involves trying to imagine the kinds of institutions and structures that would be likely to help enable a fundamental reduction in these inequalities. Such visions are unlikely to be persuasive (or useful) if they are conjured up from within the academy's ivory towers; rather, we need to experiment with ways of collaborating with communities, individuals and organisations across society, taking particular care to ensure that those whose voices are often not heard (or, some might say, ignored) are enabled to participate. Methodological approaches might, for example, involve means of co-producing research and/or employing deliberative 'minipublics' such as 'citizens' juries' or 'consensus conferences' (Escobar, 2013).

\section{Concluding Discussion}

We have used this paper to argue that, if we take seriously the multitude of evidence that points to the upstream determinants of health inequalities, then it is unrealistic to expect that these inequalities can be substantially reduced in a political and economic context in which inequalities in wealth and power are not only being sustained but actively intensified (Piketty, 2014). While it can be politically expedient for governments to make commitments to reducing health inequalities, they cannot, within current political, social and economic norms, realistically propose actions which evidence suggests will substantially reduce them such as tackling power inequalities, social status and connections, or class inequality. In this context, policy actors and researchers working in the UK have devised a parallel fantasy 
world in which proximal, downstream, easily-tackled exposures are posited as potential solutions to health inequalities. This is, we argue, a 'utopian' exercise in the sense that this word is traditionally understood; an impossible dream in which the long-established social gradient in health is gradually flattened via a series of downstream interventions and policies which, for the most part, focus on trying to change behaviours that affect health outcomes, particularly in poorer communities, rather than trying to change the social and economic environments which inform people's circumstances and decision-making. Although we have focused specifically on the UK in the context of its leadership in developing a policy programme explicitly intended to reduce health inequalities (Mackenbach, 2011), key aspects of our analysis are likely to be familiar to those working in the multitude of other countries which are currently pursuing similar economic and political strategies, such as Australia, New Zealand and the USA.

There are multiple reasons why researchers perpetuate the idea that health inequalities can be effectively reduced via relatively small-scale, downstream policy changes. One is that, like everyone else, we live within a social, economic and political context in which particular assumptions, preferences and beliefs are embedded and normalized within discourses, institutions and the various tools with which we think and communicate. Identifying these and extracting the vision of the good society to which these point is one part of what Levitas (2013) calls 'utopia as method' and this is what we have attempted, albeit briefly, in the first part of this paper. It is a vision, we suggest, in which either poorer communities are persuaded to adopt healthier behaviours at a faster rate than wealthier communities, despite their declining (in relative terms) social and economic status, or in which those communities disappear. 
The very nature of processes of institutionalization means that work which challenges the assumptions and beliefs currently embedded within society and our political institutions risks being labelled 'irrational' (Weber, 1968). It is easier, therefore, to undertake research which goes along with the mythological idea that achieving a society in which health inequalities are substantially reduced is an achievable goal within the confines of current political and economic programmes. This kind of research is eminently fundable, being not only politically appealing (Smith, 2010) but also compatible with the dominant positivist methodological paradigm to which public health subscribes. Researchers who work in this sphere may well contribute to small-scale, local-level reductions in health inequalities and, in this sense, 'make a difference', but this kind of work is highly unlikely to contribute to the substantial policy and social shifts required to achieve large-scale, population level reductions in health inequalities.

To achieve such a shift, we argue that researchers need to work with others to undertake all three strands of Levitas' (2013) 'utopia as method'. As well as identifying the utopian visions embedded within current policy programmes and public debates (the first strand) we need to reflect (collaboratively) on the kinds of people that different societies develop and encourage (the second strand) and to try to imagine, and debate, a society in which people's experiences of health and wellbeing were more equitably distributed (the third strand). This is a long way out of the realm of traditional public health science and we are not suggesting that all (or even most) researchers ought to be undertaking this kind of work. Nor are we suggesting that individual researchers ought to dedicate their time to independently developing, then promoting, very specific visions of what their preferred, 
idealised society might look like. Rather, we are simply calling for some space within current research-informed debates about health inequalities for collectively and democratically engaging with what Levitas (2013) and Goodwin and Taylor (1982) call 'speculative' work; that is combining research and experiential expertise with the imagination of people living and working in a variety of different settings to sketch out, and then debate, what kinds of societies and institutions might enable more equitable health. This is certainly not an easy task - it is not, for example, a defined and fundable research project. But if we do not start providing clearer visions of alternative future scenarios, we risk being complicit in a health inequalities research and policy 'industry' in which the same ideas are endlessly recycled and refined (Bambra et al, 2011; Smith, 2013a), whilst the macro-level context producing health inequalities remains under-examined and unchallenged by any alternatives.

\section{References}

Acheson, D, Barker, D, Chambers, J, Graham, H, Marmot, M, and Whitehead, M. (1998) Independent Inquiry Into Inequalities in Health. London: Stationery Office. American Public Health Association (2014) Healthiest Nation in One Generation https://www.apha.org/topics-and-issues/healthiest-nation Accessed 2 February 2015.

Bambra, C., Smith, K.E., Garthwaite, K., Joyce, K.E. \& Hunter, D.J. (2011) A labour of Sisyphus? Public policy \& health inequalities research in the UK from the Black \& Acheson Reports to the Marmot Review. Journal of Epidemiology \& Community Health,65:399-406. 
Bambra, C., Fox, D., and Scott-Samuel, A. (2005) Towards a politics of health. Health Promotion International 20(2): 187-193.

Bartley, M. (2003) Health Inequality: An Introduction to Concepts, Theories and Methods. Cambridge, UK: Polity.

Bartley, M., Blane, D., and Davey Smith, G. (1998) Introduction: beyond the Black Report. Sociology of Health \& Illness, 20(5): 563-77.

Bitton, J., Cavaco, A., Gaye, A. and Jones, B. (eds) (2012) United We Act a scoping study and a symposium on connected communities. URL:

\section{http://dm.ncl.ac.uk/benjones/files/2012/06/cc book download3.pdf.}

Black, D. (Chairman) (1980) Inequalities in Health: Report of a Research Working Group. London: Department of Health and Social Security.

Buck, D. and Frosini, F. (2012) Clustering of unhealthy behaviours over time: implications for policy and practice. London: The King's Fund, 2012.

Cameron, D. (2012) Speech by Prime Minister David Cameron on welfare reform, at Bluewater, Kent on Monday 25th June, 2012. Available online at: http://www.telegraph.co.uk/news/politics/david-cameron/9354163/David-Cameronswelfare-speech-in-full.html

Chaney, P. and Wincott, D. (2014), Envisioning the Third Sector's Welfare Role: Critical Discourse Analysis of 'Post-Devolution' Public Policy in the UK 1998-2012. Social Policy \& Administration, 48: 757-781. doi: 10.1111/spol.12062

Chapman, S. (2007) Public Health Advocacy and Tobacco Control - Making Smoking History, Oxford: Blackwell. 
Collin, J. (2012) The future of tobacco control: Tobacco control, global health policy and development: towards policy coherence in global governance. Tobacco Control, 21(2): 274-80.

Commission on Social Determinants of Health. (2008) Closing the gap in a generation: Health equity through action on the social determinants of health. Final Report of the Commission on Social Determinants of Health. Geneva: World Health Organization.

Crawford, R. (1977) You are dangerous to your health: the ideology and politics of victim blaming. International Journal of Health Services 7(4): 663-680.

Davey Smith, G., Dorling, D. and Shaw, M. (eds.) (2001) Poverty, inequality and health in Britain: 1800-2000 - A Reader. Bristol: The Policy Press.

Department of Health (1995) Variations In Health: What Can the Department of Health and the National Health Service Do? London: Department of Health.

Department of Health (2001) From Vision to Reality. London, Department of Health.

Department of Health (2003) Tackling Health inequalities: A Programme for Action. London: Department of Health.

Department of Health (2005) Delivering Choosing Health: Making Healthier Choices Easier. London: Department of Health.

Department of Health (2008) Health Inequalities: Progress and Next Steps. London: Department of Health.

Department of Health (2009) Tackling Health Inequalities: 10 Years On. London: Department of Health.

Dietz, R. and O'Neill, D. (2013) Enough Is Enough: Building a Sustainable Economy in a World of Finite Resources. Abingdon: Routledge. 
Drever, F. and Whitehead, M. (eds.) (1997) Health Inequalities Decennial Supplement. Series DS no. 15. Office For National Statistics. London: The Stationery Office.

Escobar, E. (2013) Final Report of the Commission on Fair Access to Political Influence. Biggar: The Jimmy Reid Foundation.

Exworthy, M., Berney, L. and Powell, M. (2002) How great expectations in Westminster are dashed locally: the local implementation of national policy on health inequalities. Policy \& Politics 30(1): 79-96.

Freudenberg, N. (2014) Lethal but Legal - Corporations, Consumption and Protecting Public Health. Oxford: Oxford University Press.

Friedli, L. (2013) 'What we've tried, hasn't worked': the politics of assets based public health. Critical Public Health, 23(2): 131-145.

Garthwaite, K., Smith, K.E., Bambra, C. and Pearce, J. (in press) Desperately Seeking Reductions in Health Inequalities: Perspectives of UK researchers on past, present and future directions in health inequalities research. Sociology of Health and IIIness.

Gilmore, A.B., Savell, E. and Collin, J. (2011) Public Health, Corporations and the New Responsibility Deal: promoting partnerships with vectors of disease? Public Health, 33(1): 2-4.

Goodwin, B. and Taylor, K. (1982) The Politics of Utopia: A study in theory and practice. London: Hutchinson University Library.

Graham, H. (1994) When Life's a Drag: Women, Smoking and Disadvantage. Norwich: HM Stationary Office.

Hall, P.A. (1993) Policy Paradigms, Social Learning, and the State: The Case of Economic Policymaking in Britain. Comparative Politics 25(3): 275-96. 
Haraway, D., Harvey, D. et al. 1995. Nature, Politics, and Possibilities: A Debate and Discussion with David Harvey and Donna Haraway. Environment and Planning A: Society and Space, 13: 507-527.

Jacoby, R. (2005) Picture Imperfect: Utopian Thought for an Anti-Utopian Age. New York: Columbia University Press.

Joyce, K.E., Smith, K.E., Sullivan, C. \& Bambra, C. (2010) 'Most of industry's shutting down up here. . .': Employability initiatives to tackle worklessness in areas of low labour market demand. Social Policy \& Society, 9(03): 337-363.

Kateb, G. (1963) Utopia and its Enemies. New York: The Free Press of Glencoe.

Kingdon, J.W. (1995 [1984]) Agendas, Alternatives, and Public Policies (2nd edn.) New York: HarperCollins College Publishers.

Kolakowski, L. (1983) The Death of Utopia Reconsidered, in McMurrin, S.C. (ed.) The Tanner Lectures on Human Values 4. Cambridge: Cambridge University Press.

Krieger, N. (2001) Theories for social epidemiology in the 21st century: an ecosocial perspective. International Journal of Epidemiology 30(4): 668-677.

Krieger, N., et al. (2010) Who, and what, causes health inequities? Reflections on emerging debates from an exploratory Latin American/North American workshop. Journal of Epidemiology and Community Health 64(9): 747-749.

Kumar, K. (1991) Utopianism. Milton Keynes: Open University Press.

Labour Party (1997) 'New Labour Because Britain Deserves Better': The Labour Party Manifesto. London: Labour Party.

Levitas, R. (2013) Utopia as Method: The Imaginary Reconstitution of Society. Basingstoke: Palgrave Macmillan. 
Link, B.G. and. Phelan J.C. (1995) Social conditions as fundamental causes of disease. Journal of Health and Social Behavior 35(extra issue): 80-94.

Mackenbach, J.P. (2010) Has the English strategy to address health inequalities failed? Social Science \& Medicine 71: 1249-53.

Mackenbach, J.P. (2011) Can we reduce health inequalities? An analysis of the English strategy (1997-2010) Journal of Epidemiology and Community Health, 5(7): 568-75.

Mackenbach, J.P. (2012). The persistence of health inequalities in modern welfare states: the explanation of a paradox. Social Science \& Medicine 75(4): 761-769.

Marmot, M. (2010) Strategic review of health inequalities in England post-2010. Marmot review final report. London: University College London.

McCormack, C. with Pallister, M. (2009) The Wee Yellow Butterfly. Argyll publishing: Edinburgh.

Mead, M. (1971) 'Towards More Vivid Utopias', chapter 2 in Kateb, G. (ed.) (1971) Utopia. New York: Atherton Press:pp41-56.

Mumford, L. (1923) The Story of Utopias: Ideal Commonwealths and Social Myths. London: George Harrap \& Co.

National Institutes of Health and U.S. Department of Health and Human Services. (2008) NIH Health Disparities Strategic Plan and Budget Fiscal Years 2009-2013.

http://www.nimhd.nih.gov/documents/NIH\%2OHealth\%20Disparities\%20Strategic\%2 OPlan\%20and\%20Budget\%202009-2013.pdf Accessed 2 February 2015.

NICE (2007) Behaviour Change at Population, Community and Individual Levels. London: National Institute for Health and Clinical Excellence.

O'Hara, M. (2014) Austerity Bites: A journey to the sharp end of cuts in the UK. Bristol: Policy Press. 
Osborne, G. (2013) Speech by the Chanceller of the Exchequer, George Osborne, on regulating the banking system, given at JP Morgan in Bournemouth on $4^{\text {th }}$ February 2013. Available online at:

http://www.telegraph.co.uk/finance/newsbysector/banksandfinance/9847127/Georg e-Osbornes-speech-in-full.html.

Oxfam (2015) Wealth: Having it all and wanting more. Oxfam issue briefing. URL: http://www.oxfam.org/sites/www.oxfam.org/files/file attachments/ib-wealthhaving-all-wanting-more-190115-en.pdf

Phelan, J.C., Link, B.G, Diez-Roux, A., Kawachi, I., and Levin, B. (2004) “Fundamental causes" of social inequalities in mortality: a test of the theory. Journal of Health and Social Behavior 45: 265-285.

Piketty, T. (2014) Capital in the Twenty-First Century. [Translated by Goldhammer, A.]. Cambridge, MA: Harvard University Press.

Popay, J., Whitehead, M. \& Hunter, D.J. (2010) Injustice if killing people on a large scale but what is to be done about it? Journal of Public Health, 32(2): 148-9.

Raphael, D. (2012) (ed.) Tackling Health Inequalities: Lessons from International Experiences. Toronto: CSPI.

Saunders, P. 2010. Beware False Prophets: Equality, the Good Society and The Spirit Level, London, Policy Exchange.

Sayer, A. (2014) Why We Can't Afford the Rich. Policy Press: Bristol.

Scambler, G. (2007) Social structure and the production, reproduction and durability of health inequalities, Social Theory and Health, 5(4): 297-315.

Scambler, G. (2009) Capitalists, workers and health: illness as a 'side-effect' of profit-making, Social Theory and Health, 7(2): 117-28. 
Scambler,G. (2012) Review article: health inequalities. Sociology of Health and IIIness, 34:

130-146.

Schmidt, V. (2010) Taking ideas and discourse seriously: explaining change through discursive institutionalism as the fourth 'new institutionalism'. European Political Science Review 21(1): 1-25.

Schrecker, T. 2013. Can health equity survive epidemiology? Standards of proof and social determinants of health. Preventive medicine, 57, 741-744.

Schulz, A.J. and Mullings, L. (eds.) (2006) Gender, Race, Class and Health: Intersectional Approaches. San Francisco: Jossey Bass.

Scott, S., Curnock, E., Mitchell, R., Robinson, M., Taulbut, M., Tod, E., and McCartney, G. (2013) What Would it Take to Eradicate Health Inequalities? Testing the Fundamental Causes Theory of Health Inequalities in Scotland. Glasgow: NHS Health Scotland. URL: http://www.scotpho.org.uk/downloads/scotphoreports/scotpho131018_whatwouldit take_report.pdf -

Scottish Executive (2000). Our National Health: A plan for action, a plan for change. Edinburgh: Scottish Executive.

Scott-Samuel, A., et al. (2014) The impact of Thatcherism on health and well-being in Britain. International Journal of Health Services, 44(1): 53-71.

Scottish Executive (2005). Delivering for Health. Edinburgh: Scottish Executive.

Shildrick, T., MacDonald, R., Webster, C., and Garthwaite, K. (2012) Poverty and Insecurity: Life in low-pay, no-pay Britain, Bristol: Policy Press.

Slater, T. (2014) 'The myth of 'Broken Britain': welfare reform and the production of ignorance', Antipode 46 (4):948-969 
Smith, K.E. (2013a) Beyond Evidence Based Policy in Public Health: The Interplay of Ideas. Basingstoke: Palgrave Macmillan.

Smith, K.E. (2013b) Institutional Filters: The Translation and Re-Circulation of Ideas about Health Inequalities within Policy. Policy \& Politics, 41(1): 81-100.

Smith, K.E. (2010) Research, Policy and Funding - Academic treadmills and the squeeze on intellectual spaces. The British Journal Of Sociology, 61(1): 176-195.

Smith, K.E., Hunter, D.J., Blackman, T., Williams, G., McKee, L., Harrington, B., Elliott, E., Marks, L. and Greene, A. (2009) 'Divergence or Convergence? Health Inequalities \& Policy in a Devolved Britain' Critical Social Policy 29(2): 216-42.

Smith, K.E. and Kandlik Eltanani, M. (2015) What kinds of policies to reduce health inequalities in the UK do researchers support? Journal of Public Health. 37(1): 6-17

Snowdon, C. (2010) The Spirit Level Delusion: Fact-checking the Left's New Theory of Everything, Washington, DC: Democracy Institute / Little Dice.

Springett, J. and Scott-Samuel, A. (2007) Hegemony or health promotion? Prospects for reviving England's lost discipline. Journal of the Royal Society of Health 127: 211-214. SurgeonGeneral.gov. Elimination of Health Disparities.

http://www.surgeongeneral.gov/initiatives/prevention/strategy/elimination-ofhealth-disparities.html Accessed 2 February 2015.

Weber, M. (1968) Charismatic Authority and its Routinization. In S.N. Eisenstadt (ed.) Max Weber - On Charisma and Institution Building. Chicago and London: The University of Chicago Press: 48-65.

Whitehead, M. and Dahlgren, G. (2007) Concepts and Principles for Tackling Social Inequalities in Health. Levelling Up (Part 1). Copenhagen: World Health Organization. http://www.euro.who.int/document/e89383.pdf Accessed 2 February 2015. 
Wilkinson, R. and Pickett, K. (2009) The spirit level: Why more equal societies almost always do better. London: Penguin.

Wright, S. (2012) Welfare-to-work, Agency and Personal Responsibility. Journal of Social Policy, 41(2): 309-28.

Word count: 6,113 excluding abstract and references; 8,175 including abstract and references.

Date: $6^{\text {th }}$ May 2015 